\title{
CARACTERIZAÇÃO E QUALIDADE DE FRUTOS DE LIMÃO ‘GALEGO’
}

José Roberto Chaves Neto ${ }^{1}$, Silvanda de Melo Silva ${ }^{2}$, Luana Ferreira dos Santos ${ }^{2}$

${ }^{1}$ Universidade Federal de Santa Maria- UFSM. ${ }^{2}$ Universidade Federal da Paraíba - UFPB, Docente no Departamento de Ciências Fundamentais e Sociais, Areia, PB. E-mail: jose.chavesneto@gmail.com

\section{RESUMO}

Este trabalho teve por objetivo avaliar as características físicas e físico-químicas de limão 'Galego' (Citrus aurantifolia Swingle) em diferentes estádios de maturação, oriundos de propriedades de agricultura familiar do município de Matinhas, PB. Para as avaliações físicas foram considerados, o comprimento e diâmetro do fruto; a massa fresca do fruto e rendimento de suco; já para as avaliações físico-químicas a polpa dos frutos foi submetida às determinações do $\mathrm{pH}$; sólidos solúveis (SS); acidez titulável (AT); relação sólidos solúveis/acidez titulável (SS/AT) e ácido ascórbico. Houve diferença significativa entre os estádios de maturação para as variáveis diâmetro, massa fresca e rendimento de suco, acidez titulável e ácido ascórbico. Os frutos de limão apresentaram incremento no diâmetro e rendimento de polpa, redução da acidez titulável e do ácido ascórbico, já o $\mathrm{pH}$, os sólidos solúveis e a relação SS/AT não variaram com o avanço da maturação. Com base nos aspectos de qualidade avaliados, o limão galego de Matinhas, PB, Brasil apresenta qualidade satisfatória para o mercado.

Palavras-chave: Citrus aurantifolia Swingle; características físicas; características físico-químicas; ácido ascórbico.

\section{CHARACTERIZATION AND QUALITY OF 'GALEGO' LEMON FRUITS DURING MATURATION}

\section{ABSTRACT}

The objective of this work was to evaluate the physical and physicochemical characteristics of lemon 'Galego' (Citrus aurantifolia Swingle) in different maturation stages, from family farms in Matinhas, PB, Brazil. For the physical evaluations were considered, the length and diameter of the fruit; fresh fruit mass and juice yield; already for the physical-chemical evaluations of the pulp of the fruits was submitted to the determinations of the $\mathrm{pH}$; soluble solids (SS); titratable acidity (TA); soluble solids / titratable acidity ratio (SS/AT) and ascorbic acid. There was a significant difference between the maturation stages for the variables diameter, fresh mass and juice yield, titratable acidity and ascorbic acid. Lemon fruits presented increase in pulp diameter and yield, titratable acidity and ascorbic acid reduction. $\mathrm{pH}$, soluble solids and SS/AT ratio did not vary with the advancement of maturation. Based on the aspects of quality evaluated, the lemon 'Galego' from Matinhas, PB, Brazil presents satisfactory quality for the market.

Keywords: Citrus aurantifolia Swingle; physical characteristics; physical-chemical characteristics; ascorbic acid.

\section{INTRODUÇÃO}

A fruticultura é tida como atividade econômica promissora em todo o mundo, em função da grande variedade espécies, com diferentes sabores e aromas (MACEDO et al., 1995). O Brasil apresenta uma grande diversidade de espécies frutíferas, sendo o terceiro maior produtor mundial de frutas com base nas dez frutíferas mais produzidas (RITZINGER et al., 2008). Dentre estas espécies, destacam-se as frutíferas cítricas, que são as frutas mais produzidas no mundo, sendo os maiores produtores de citros a China, índia, México, Argentina e Brasil. No Brasil o cultivo dos citros foi introduzido no período colonial, passando a ter grande importância nos hábitos de consumo da população até a atualidade (COUTO; CANNIATTI-BRAZACA, 2010; COUTO et al., 2010; SOUZA et al., 2015) 
A produção brasileira de limão em 2016, foi de 1.262,353 toneladas, em uma área total de 47.279 ha $^{-1}$ plantadas, com produção média de 26,70 toneladas por hectare. A Região Sudeste é líder absoluta na produção da fruta, representando $78,67 \%$ do total de produção, sendo os estados maiores produtores São Paulo (875.445 toneladas), Bahia (148.992 toneladas) e Minas Gerais (86.352 toneladas) (ANUÁRIO BRASILEIRO DE CITROS, 2016). O estado da Paraíba apresenta uma baixa produção de limão, ocupando o décimo oitavo lugar na produção brasileira, com 1.999 toneladas, em uma área de 295 hectare (IBGE, 2017).

Os frutos cítricos, principalmente laranjas doces, tangerinas e limões (diversas espécies), fazem parte da dieta da maioria da população brasileira. Estes frutos são fonte de vitaminas, fibras e metabólitos secundários com atividades antioxidantes incluindo ácido ascórbico, compostos fenólicos, flavonoides e limonoídes, que são importantes para a nutrição humana (JAYAPRAKASHA; PATIL, 2007; COUTO et al., 2010).

Nas diferentes regiões do Brasil, o limão é facilmente encontrado, sendo produzido e consumido durante todo o ano, nas suas diversas variedades, embora sendo mais produtivo de dezembro a maio. Dentre as variedades destacase o limoeiro 'Galego' (Citrus aurantifolia Swingle), que é uma espécie frutífera pertencente à família das Rutáceas, de porte arbustivo e ramos cheios de espinhos, chegando a atingir de 4 a 5 metros de altura. Este fruto é classificado dentro das limas ácidas e no estado da Paraíba o limão galego é produzido em propriedades de agricultura familiar, principalmente no município de Matinhas, PB, portanto, ainda são poucos os pomares no estado que produzem em escala comercial.

O fruto do limoeiro 'Galego' (Citrus aurantifolia Swingle) é redondo, pequeno e muito suculento. Apresenta casca fina e lisa, de cor verde ou amarela clara. A polpa tem de cinco a seis sementes, é rica em suco e de sabor ácido, porém agradável. Bastante comum nos quintais do Nordeste e Centro-oeste brasileiro, onde a produtividade de frutos por pé é exuberante (TRUCOM, 2005). Em geral, todas as variedades do limão apresentam aspectos básicos semelhantes, ficando a diferenciação na cor, tamanho, forma e textura da casca, que pode ser desde lisa, como no limão galego, até muito enrugada como no limão cravo (Citrus limonia Osbeck).

O limão 'Galego' é apreciado em todo o mundo, não só pelo seu sabor, mas também por ser fonte natural de carboidratos, carotenoides, ácido cítrico, ácido ascórbico e sais minerais, além de pectina na entrecasca, e óleos monoterpênicos na casca. Uma mudança apropriada na dieta em relação à inclusão de componentes encontrados em frutas e suco de frutas pode ser importante na prevenção de doenças e para uma vida mais saudável (PINHEIRO, 2006).

Os frutos cítricos durante a fase de maturação apresentam uma reduzida taxa de crescimento. Nesse estádio também ocorre aumento nos teores de sólidos solúveis, principalmente açúcares, e de compostos nitrogenados, aminoácidos em sua maioria e uma concomitante redução de ácidos orgânicos. O grau de maturação no momento da colheita também é aspecto importante, visto que condiciona a qualidade pós-colheita. Frutas cítricas colhidas muito maduras apresentam pouca firmeza, maior suscetibilidade a injúrias mecânicas, podridões, alterações fisiológicas e possuem uma menor vida de prateleira. Sendo os teores de sólidos solúveis, acidez do suco cítrico e a razão sólidos solúveis pela acidez parâmetros que vêm sendo utilizados para a avaliação da maturação dos citros (AGUSTí et al., 1996; CHITARRA; CHITARRA, 2005; PEREIRA et al., 2006).

De acordo com Chitarra e Chitarra, (2005) durante o desenvolvimento dos frutos, ocorrem uma série de transformações endógenas em consequência de seus metabolismos específicos. Mcatee et al. (2013) descrevem que durante a fase de maturação surgem diversas alterações fisiológicas e bioquímicas que promovem o desenvolvimento do aroma e do sabor, assim como da aparência, na qual se destaca alterações na coloração da casca, evidenciando a máxima qualidade sensorial e nutricional que definem a sua aceitação no mercado (PALIYATH et al., 2008).

Desse modo, o desenvolvimento de pesquisas direcionadas ao conhecimento das mudanças nas características físicas e físicoquímicas durante a evolução da maturação dos frutos, por meio de investigações científicas e tecnológicas são fundamentais, gerando informações quanto a disponibilidade de nutrientes, além de definir o ponto de colheita e 
permitir a manutenção da qualidade póscolheita, para fornecer ao consumidor novos produtos derivados de frutas (DANTAS et al., 2013; BRITO et al., 2017). Assim, este trabalho teve por objetivo avaliar as características físicas e físico-químicas de limão 'Galego' em diferentes estádios de maturação, oriundo de propriedades de agricultura familiar do município de Matinhas, PB.

\section{MATERIAL E MÉTODOS}

Os frutos do limoeiro 'Galego' (Citrus aurantifolia Swingle) foram avaliados no Laboratório de Biologia e Tecnologia PósColheita, no Centro de Ciências Agrárias (CCA), da Universidade Federal da Paraíba (UFPB).

Os frutos foram colhidos de 15 plantas pela manhã de um pomar de agricultura familiar do Município de Matinhas, PB, Brasil, em seguida, acondicionados em caixas térmicas e transportados para o laboratório. No laboratório os frutos foram selecionados, descartando-se aqueles com danos físicos e ou acometidos por ataque de pragas e doenças. Em seguida, lavados em água corrente e imersos em solução aquosa contendo hipoclorito de sódio $\left(5 \mathrm{mg} . \mathrm{L}^{-1}\right)$ por 3 minutos. Após lavagem e sanitização os frutos foram selecionados, quanto ao estádio de maturação com base na coloração e apresentação da superfície da casca, em verde (V), "de vez" (DV) e maduro (M).

Para as avaliações físicas foram utilizados, 30 frutos, sendo cada fruto uma repetição. Estes frutos foram avaliados quanto o comprimento e diâmetro, determinado com auxílio de um paquímetro digital (Within $300 \mathrm{~mm}$ ), e os resultados expressos em milímetros $(\mathrm{mm}) ; \mathrm{a}$ massa fresca, determinada pela pesagem de cada fruto isoladamente com o auxílio de uma balança semi-analítica (A42207c - Bel Engeneering), e os resultados expressos em gramas (g), e o rendimento de polpa, determinado pelo isolamento da parte e subsequente pesagem em balança semi-analítica (A 42207c - Bel Engeneering), e os resultados expresso em porcentagem (\%).

Para as avaliações físico-químicas, foram utilizadas 3 repetições de 10 frutos para cada estádio de maturação. As avaliações foram realizadas após homogeneização do suco. Em triplicata, foram realizadas as seguintes análises: potencial hidrogeniônico $(\mathrm{pH})$, determinado com potenciômetro digital (Hanna, Singapura), de acordo com a AOAC (2016); acidez titulável (AT), determinada por titulometria com $\mathrm{NaOH} \mathrm{0,1} \mathrm{M,}$ de acordo com Brasil (2008), resultados expressos em \% de ácido cítrico; sólidos solúveis (SS), determinados com refratômetro digital (Krüss-Optronic, Hamburgo, Alemanha), conforme normas analíticas do Instituto Adolfo Lutz (2005), resultados expresso em \%, e ácido ascórbico, determinado por titulometria com a solução DFI (2,6 dicloro-fenol-indofenol 0,002 \%), conforme método de Strohecker e Henning (1967), e os resultados expressos em mg de ácido ascórbico $100 \mathrm{~g}^{-1}$.

O delineamento experimental utilizado foi o inteiramente casualizado. Os dados foram submetidos à análise de variância (ANOVA) e as médias comparadas pelo teste de Tukey ao nível de $5 \%$ de probabilidade de erro $(p \leq 0,05)$, utilizando o programa estatístico SISVAR versão 5.6 (FERREIRA, 2014). Na análise multivariada fezse uso da análise de correlação linear simples utilizando-se o software Statistica 7.0.

\section{RESULTADOS E DISCUSSÃO}

As características físicas e físico-químicas dos frutos sofrem influência das condições edafoclimáticas, dos tratos culturais, época de colheita, constituição genética, estádio de maturação e do tratamento pós-colheita, entre outros. Estas características determinam fatores de qualidade essenciais para a utilização e comercialização da polpa dos frutos e para elaboração de produtos industrializados (FAGUNDES; YAMANISHI, 2001; CARVALHO et al., 2003; CHITARRA; CHITARRA, 2005).

Os comprimentos dos frutos de limão 'Galego' não diferiram significativamente ( $p \leq$ $0,05)$ entre os estádios de maturação avaliados, com variação de 51,11 a $57 \mathrm{~mm}$. Com relação ao diâmetro dos frutos, houve diferença significativa ( $p \leq 0,05)$, entre os estádios de maturação avaliados oscilando de 51,66 a 60,88 mm, cuja média foi de 55,88 . Os frutos dos estádios $\mathrm{M}$ e DV apresentaram valores superiores com 60,88 e $55,11 \mathrm{~mm}$, respectivamente (Tabela 1).

Os resultados médios de comprimento e diâmetro dos frutos de limão 'Galego' estudado neste trabalho, foram próximos aos encontrados por Goes et al. (2012), que relataram valores de $68,86 \mathrm{~mm}$ para o comprimento e diâmetro de $56,93 \mathrm{~mm}$, em frutos de limão 'Tahiti' colhidos verdes (casca verde), no município de Guaraciaba do Norte, CE. Estas características físicas são de grande importância frutos em frutos in natura destinados ao processamento pela indústria, pois 
influencia diretamente no tempo de secagem, interferindo no custo de produção devido à demanda energética (VIANA et al., 2017).

$O$ peso do fruto está diretamente relacionado com estádio de desenvolvimento e/ou maturação exceto no estádio em que o fruto se encontra em estado avançado de maturação (GOES et al., 2012). De acordo com Chitarra e Chitarra (2005) os frutos mais pesados e de maior tamanho, são mais atrativos aos consumidores, e consequentemente destinados ao mercado de frutas frescas.

A massa fresca dos frutos aumento com o avanço da maturação, sendo constatado diferença significativa ( $p \leq 0,05)$, entre os estádios de maturação, com valores variando de 122,43 a $129,43 \mathrm{~g}$ do estádio de maturação $\mathrm{V}$ para $\circ \mathrm{M}$, não diferindo significativamente do estádio DV $(124,86 \mathrm{~g})$. Estes valores foram superiores ao constatado por Martins et al., (2018) que verificaram frutos com massa fresca média de 56,25 g, para esta mesma fruta, oriundas de Uberlândia, MG. Valores semelhantes foram citados por Goes et al. (2012), que reportaram valores variando entre 120,74 a 128,06 g, com média geral de 123,87 g, em limão 'Tahiti', provenientes do Recôncavo Sul da Bahia. Resultados superiores de massa fresca foram citados por Martins et al., (2018), que ao avaliarem frutos de limão 'Tahiti' cultivados em condições de Cerrado, descreveram massa média de $148,49 \mathrm{~g}$.

O rendimento de suco dos frutos de limão 'Galego' diferiu significativamente $(p \leq$ 0.05 ), entre os estádios de maturação, com média de 53,40 \% com destaque para o estádio DV e $M$, que apresentaram os maiores rendimentos (56,09 e 69,45\%), respectivamente, sendo iguais entre si e diferindo significativamente do estádio $\mathrm{V}$ (Tabela 1). Valores semelhantes foram citados por Martins et al. (2018), que reportaram rendimento médio de suco de $18,00 \%$, nesta mesma fruta, provenientes de Uberlândia, MG. Em contrapartida, Souza et al. (2015) e Martins et al. (2018) reportaram valores superiores de rendimento de suco, com médias de 31,15 e 50,9 $\%$ de rendimento de suco, respectivamente, em frutos de limão 'Tahiti'.

A porcentagem de polpa está relacionada com o rendimento do fruto ambos, portanto, diretamente proporcionais. O rendimento de polpa médio do limão 'Galego' avaliado neste trabalho foi superior ao valor mínimo estipulado pelo Padrão de Identidade e Qualidade (PIQ) do Ministério da Agricultura, Pecuária e do Abastecimento (MAPA), que determina percentual médio de rendimento mínimo de 40 $\%$, apresentaram características satisfatórias para industrialização (BRASIL, 1999).

Tabela 1. Características físicas de frutos de limão 'Galego' (Citrus aurantifolia Swingle) colhidos em três estádios de maturação. Areia, PB.

\begin{tabular}{ccccc}
\hline Estádio de Maturação & $\begin{array}{c}\text { Comprimento } \\
\text { (mm) }\end{array}$ & $\begin{array}{c}\text { Diâmetro } \\
(\mathbf{m m})\end{array}$ & $\begin{array}{c}\text { Massa fresca } \\
\mathbf{( g )}\end{array}$ & $\begin{array}{c}\text { Rend. de suco } \\
\text { (\%) }\end{array}$ \\
\hline V & $51,44 \pm 0,02 \mathrm{a}$ & $51,66 \pm 0,32 \mathrm{~b}$ & $122,43 \pm 0,32 \mathrm{~b}$ & $53,40 \pm 0,02 \mathrm{~b}$ \\
DV & $51,11 \pm 0,22 \mathrm{a}$ & $55,11 \pm 0,25 \mathrm{ab}$ & $124,86 \pm 0,04 \mathrm{ab}$ & $56,09 \pm 0,06 \mathrm{a}$ \\
M & $57,00 \pm 1,50 \mathrm{a}$ & $60,88 \pm 1,58 \mathrm{a}$ & $129,44 \pm 1,87 \mathrm{a}$ & $69,45 \pm 1,03 \mathrm{a}$ \\
\hline Média Geral & 53,18 & 55,88 & 125,58 & 16,31 \\
CV (\%) & 6,03 & 4,72 & 9,50 & 11,21 \\
\hline
\end{tabular}

*Medias seguidas pela mesma letra na coluna não diferem entre si pelo teste de Tukey ao nível de $5 \%$ de probabilidade.

$\mathrm{O}$ pH dos frutos de limão 'Galego' não diferiu significativamente $(p \leq 0,05)$ entre os estádios de maturação, cuja média foi de 2,69 (Tabela 2). Valores baixos de pH são apreciados pela indústria de processamento de frutos, por dificultar o desenvolvimento de microrganismos, não necessitando o tratamento térmico elevado, evitando assim perda de qualidade nutricional e permitindo a conservação dos alimentos. Já valores mais elevados de $\mathrm{pH}$ é preferência para o mercado de frutas frescas (BENEVIDES et al., 2008; GONDIM et al., 2013).

Os valores de $\mathrm{pH}$ dos frutos de limão 'Galego' avaliados neste trabalho, foram ligeiramente superiores aos encontrados por Miranda e Junior (2010), que constataram valor médio de 2,10, em frutos de limão 'Tahiti'. Valores próximos foram citados por Goes et al. (2012), que constataram valore de $\mathrm{pH}$ variando de 2,06 a 2,17 para frutos oriundos do Recôncavo Sul da Bahia, BA. Valores semelhantes também 
foram relatados por Brito et al. (2017), que descreveram $\mathrm{pH}$ médio de 2,07, para frutos de limão 'Tahiti'. Por outro lado, Souza et at. (2015), reportaram valores superiores de $\mathrm{pH}$, com média de 2,85, para frutos de limão 'Tahiti, provenientes de Triunfo, PE.

O teor de sólidos solúveis (SS) dos frutos de limão 'Galego', não diferiu significativamente entre os estádios de maturação (Tabela 2), os valores oscilaram entre 5,93 a 6,40\%, com média de $6,13 \%$. Resultados de sólidos solúveis semelhantes foram observados por Souza et al. (2015) e Martins et al. (2018), que encontraram teor médio de 7,40 e 7,91 \%, em frutos de limão 'Tahiti'. No entanto, foi inferior aos resultados obtidos por Goes et al. (2012), que constataram teor médio variando entre 10,66 a 11,16 \%, para frutos de limão 'Tahiti' provenientes do Recôncavo Sul da Bahia.

A acidez titulável (AT) dos frutos de limão galego diminuiu com a maturação, havendo diferença significativa $(p \leq 0,05)$ entre os estádios de maturação, tendo os $\mathrm{V}$ e DV os maiores valores com 4,68 e 4,64 g.100 $\mathrm{g}^{-1}$ de ácido cítrico, respectivamente, sendo iguais entre si e diferindo significativamente do estádio $\mathrm{M}$, que apresentou o menor valor com $3,88 \mathrm{~g} \cdot 100 \mathrm{~g}^{-1}$ de ácido cítrico (Tabela 2).

A elevada AT encontrada neste estudo para os frutos de limão 'Galego' não o classificam como um fruto de sabor ideal para o mercado de consumo de fruta fresca, visto que segundo Sacramento et al. (2007), uma fruta pode ser classificada de sabor moderado quanto a AT e bem aceita para este mercado, quando apresentar acidez titulável entre 0,08 e 1,95\% de ácido cítrico. A AT encontrada neste estudo foi inferior ao reportado por Goes et al. (2012), que relataram valores oscilando entre 5,39 a 5,95\% de ácido cítrico, em frutos de limão 'Tahiti' provenientes do Recôncavo Sul da Bahia. Valores superiores também foram relatados por Kluge et al. (2007), Miranda e Junior (2010) e Brito et al. (2017), que constataram teores médios de 6,00, $5,77,6,75 \%$ de ácido cítrico, respectivamente, em frutos de limão 'Tahiti'.

A relação SS/AT, descreve o equilíbrio entre os sólidos solúveis e a acidez, sendo tido como um parâmetro importante para avaliar a qualidade dos frutos constituindo-se numa das formas mais usuais de se avaliar o sabor por representar de modo mais significativo. Além disso, a razão sólidos solúveis/acidez titulável pode servir como indicadora do estádio de maturidade fisiológica de frutos de várias espécies (CHITARRA; CHITARRA, 2005; SILVA et al., 2012).

Os resultados para a relação SS/AT encontrados neste trabalho para os frutos de limão 'Galego', não diferiram significativamente $(p \leq 0,05)$ durante a maturação, com variação de 1,30 a 1,52, apresentando média geral de 1,39, indicando que não houve variação no sabor dos frutos durante a maturação (Tabela 2). Estes valores foram próximos aos observados por Miranda e Junior (2010), que encontraram valores médios de 1,56 em frutos de limão 'Tahiti' oriundos de Colorado do Oeste, RO. Kluge et al. (2007), quando analisaram a qualidade de frutos de limão "Tahiti", reportaram média de relação SS/AT oscilados entre 1,37 e 1,64. Resultados superiores, foram reportados por Goes et al. (2012), com média de 1,96 em frutos de limão "Tahiti" oriundos de Guaraciaba do Norte, CE.

Segundo Santos et al. (2010), um parâmetro nutricional de grande importância é o conteúdo de ácido ascórbico que está presente naturalmente nas frutas, e apresenta elevado poder antioxidante, atuando na prevenção e combate de diversas doenças.

O conteúdo de ácido ascórbico dos frutos de limão 'Galego' diminuiu com a maturação, sendo observado diferença significativa $(p \leq 0,05)$ entre os estádios de maturação, com destaque para os estádios DV e $\mathrm{V}$ que apresentaram os maiores conteúdos $\left(37,58\right.$ e $\left.39,97 \mathrm{mg} \cdot 100 \mathrm{~mL}^{-1}\right)$, respectivamente, mas decaindo significativamente $(p \leq 0,05)$ no final da maturação para $31,37 \mathrm{mg}^{1} 100 \mathrm{~mL}^{-1}$, no estádio $\mathrm{M}$ (Tabela 2).

O conteúdo médio de ácido ascórbico encontrado neste trabalho, foi de 36,31 mg. $100 \mathrm{~mL}^{-1}$, estando acima do mínimo estabelecido que é de $20,00 \mathrm{mg} \cdot 100 \mathrm{~mL}^{-1}$ pelo regulamento técnico (BRASIL, 2005), para determinação de padrões de identidade e qualidade para suco de limão. Valores semelhantes foram reportados por Bassan et al. (2016), que descreveram conteúdo médio de $33,58 \mathrm{mg} \cdot 100 \mathrm{~mL}^{-1}$, para frutos de limão 'Tahiti' provenientes de pomares comerciais, localizados no município de Itajobi, SP. 
Tabela 2. Características físico-químicas de frutos de limão 'Galego' (Citrus aurantifolia Swingle) colhidos em três estádios de maturação. Areia, PB.

\begin{tabular}{|c|c|c|c|c|c|}
\hline $\begin{array}{l}\text { Estádio de } \\
\text { Maturação }\end{array}$ & pH & $\begin{array}{l}\text { SS } \\
\text { (\%) }\end{array}$ & $\begin{array}{c}\text { AT } \\
\text { (g.100 }{ }^{-1} \text { ác.cítrico) }\end{array}$ & SS/AT & 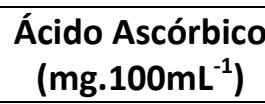 \\
\hline $\mathrm{V}$ & $2,67 \pm 0,02 a$ & $6,40 \pm 0,03 a$ & $4,68 \pm 0,01 a$ & $1,36 \pm 0,02 a$ & $37,58 \pm 0,03 a b$ \\
\hline DV & $2,65 \pm 0,04 a$ & $6,06 \pm 0,02 a$ & $4,64 \pm 0,02 a$ & $1,30 \pm 0,02 a$ & $39,97 \pm 0,03 a$ \\
\hline $\mathrm{M}$ & $2,74 \pm 0,02 a$ & $5,93 \pm 0,03 a$ & $3,880,03 \mathrm{~b}$ & $1,520,01 a$ & $31,37 \pm 0,37 b$ \\
\hline Média Geral & 2,69 & 6,13 & 4,40 & 1,39 & 36,31 \\
\hline CV (\%) & 2,39 & 3,60 & 5,87 & 6,89 & 7,33 \\
\hline
\end{tabular}

* Medias seguidas pela mesma letra na coluna não diferem entre si pelo teste de Tukey ao nível de $5 \%$ de probabilidade.

Por outro lado, Miranda e Junior (2010) e Brito et al. (2017), constataram valores superiores aos encontrados neste trabalho, com médias de 27,97 e $28,40 \mathrm{mg}^{\circ} 100 \mathrm{~mL}^{-1}$ de ácido ascórbico, respectivamente, em frutos de limão "Tahiti". No entanto, Goes et al. (2012) reportaram valores bem superiores aos encontrados neste trabalho, com conteúdo variando de 46,00 a $60,56 \mathrm{mg} \cdot 100 \mathrm{~g}^{-1}$, em frutos de limão "Tahiti" oriundos de Guaraciaba do Norte, CE.

Observou-se, na Tabela 3, correlação positiva para todas as variáveis físicas dos frutos de limão 'Galego', sendo significativa estatisticamente $(p \leq 0,05)$, as correlações entre as variáveis diâmetro com a massa fresca, diâmetro com o rendimento de polpa e massa fresca com o rendimento de polpa dos frutos.

As correlações positivas significativas $(p \leq 0,05)$ para as características físicas dos frutos de limão 'Galego' foram entre as variáveis diâmetro $x$ rendimento de polpa, massa fresca $x$ rendimento de polpa e diâmetro $x$ massa fresca. Indicando que, quanto maior o diâmetro do fruto, maior a massa fresca, como também o rendimento de polpa. As correlações positivas entre duas características, indicam que estas são beneficiadas ou prejudicadas pelas mesmas causas de variação (NASCIMENTO et al., 2014).

Os maiores valores de correlações observados foram para o diâmetro $\mathrm{x}$ rendimento de polpa $(0,996)$, massa fresca $x$ rendimento de polpa $(0,993)$ e diâmetro $x$ massa fresca $(0,952)$. De acordo com a classificação de intensidade de correlação citada por Guerra e Liveira (1999), $p \leq$ 0,05 é considerada muito forte $(r \pm 0,91$ a $\pm 1,00)$, forte $(r \pm 0,71$ a $\pm 0,90)$, média $(r \pm 0,51$ a $\pm 0,70)$ e fraca $(r \pm 0,31$ a $\pm 0,50)$. Portanto, a correlação positiva e significa entre estas características é classificada intensidade muito forte.

Tabela 3. Correlação linear simples entre as características físicas de frutos de limão 'Galego' (Citrus aurantifolia) colhidos em três estádios de maturação.

\begin{tabular}{ccc}
\hline Correlação & Coeficiente de correlação (r) & Significância \\
\hline Comprimento x Diâmetro & 0,909 & $\mathrm{~ns}$ \\
Comprimento x Massa fresca & 0,921 & $\mathrm{~ns}$ \\
Comprimento x Rendimento de polpa & 0,872 & $\mathrm{~ns}$ \\
Diâmetro x Massa fresca & 0,952 & $*$ \\
Diâmetro x Rendimento de polpa & 0,996 & $*$ \\
Massa fresca x Rendimento de polpa & 0,993 & $*$ \\
\hline
\end{tabular}

*Significativo ao nível de $5 \%$ de probabilidade $(p \leq 0,05),{ }^{\text {ns }}$ Não significativo.

Para as características físico-químicas dos frutos de limão 'Galego' pôde-se observar que as correlações pH x SS $(-0,549)$ e AT x Ácido Ascórbico $(0,950)$ não foram estatisticamente significativas (Tabela 4), porém foi significativa ( $p$ $\leq 0,05)$ a correlação entre as variáveis $\mathrm{pH} \times$ Ácido Ascórbico (-0,998), apresentando correlação negativa, indica que $\mathrm{o}$ aumento do $\mathrm{pH}$ é inversamente proporcional ao aumento do conteúdo de ácido ascórbico.

Houve correlação significa entre $\mathrm{pH} \times$ Acidez $\left(-0,867^{*}\right)$ dos frutos de limão 'Galego', apresentando correlação negativa (Tabela 4), mostrando que quanto menor for a acidez titulável, maior será o pH. Esta mesma correlação foi observada por Silva et al. (2018) para dos frutos de manga Ubá, que descrevem como 
consequência dessa correlação a redução da estabilidade das pectinas da parede celular, o que facilita a ação da enzima poligalacturonase, reduzindo a consistência da polpa do fruto.

A correlação significativa entre AT $\mathrm{x}$ ácido ascórbico (0,950*) dos frutos de limão 'Galego', foi positiva e classificada como de intensidade muito forte (Tabela 4), sinal de que o aumento da
AT é diretamente proporcional ao aumento do conteúdo de ácido ascórbico. Esta correlação também foi verificada por Silva et al. (2012) e Silva et al. (2018), para frutos de manga 'Uba'. Estes autores relatam que o ácido ascórbico, assim como o ácido cítrico presente em mangas diminui com o amadurecimento.

Tabela 4. Correlação linear simples entre as características físico-químicas de frutos de limão 'Galego' (Citrus aurantifolia Swingle) colhidos em três estádios de maturação.

\begin{tabular}{ccc}
\hline Correlação & Coeficiente de correlação (r) & Significância \\
\hline pH x SS & $-0,549$ & ns \\
pH x AT & $-0,867$ & $*$ \\
pH x Ácido Ascórbico & $-0,998$ & $*$ \\
SS x AT & 0,744 & $\mathrm{~ns}$ \\
SS x Ácido Ascórbico & 0,499 & $\mathrm{~ns}$ \\
AT x Ácido Ascórbico & 0,950 & $*$ \\
\hline
\end{tabular}

* Significativo ao nível de $5 \%$ de probabilidade $(p \leq 0,05),{ }^{\text {ns }}$ Não significativo.

Realizar estudos que permitam correlacionar parâmetros de qualidade de frutos de interesse agronômico, relacionando as características físicas e físico-químicas de frutos gerando informações de interesse tanto para o mercado de frutas frescas, como também para a agroindústria é de grande importância. Além dos aspectos relacionados a forma de exploração e comercialização dos frutos também é possível fornecer informações aos melhoristas, visto que a eficiência da seleção de genótipos promissores é aumentada e em muitos casos obtida conjuntamente, com base na utilização de características correlacionadas (BORGES et al., 2011; SILVA et al.; 2013; SILVA et al., 2018).

\section{CONCLUSÕES}

Os frutos de limão 'Galego' provenientes de Matinhas, PB, apresentaram incremento no diâmetro e rendimento de polpa, redução da acidez titulável e do ácido ascórbico. Já o $\mathrm{pH}$, os sólidos solúveis e a relação SS/AT não variam com o avanço da maturação.

Com base nos aspectos de qualidade avaliados, o limão 'Galego' de Matinhas, PB, apresenta qualidade satisfatória para o mercado.

\section{AGRADECIMENTOS}

Ao Conselho Nacional de Desenvolvimento Científico e Tecnológico (CNPq) pelo auxílio financeiro na execução do presente trabalho e pela concessão da bolsa de iniciação cientifica ao primeiro autor.

\section{REFERÊNCIAS}

AGUSTÍ, M.; ALMELA, V.; AZNAR, M.; JUAN, M.; PERES, V. Citros: desenvolvimento e tamanho final do fruto. Porto Alegre: Ivo Mânica e tradutor, 1996. $102 \mathrm{p}$.

ANUÁRIO BRASILEIRO DE CITROS 2016. Rio Grande do Sul: Gazeta Santa Cruz, 2016. p. 5053.

AOAC. Official methods of analysis of the Association of Official Analytical Chemistry. 20. ed. Washington: AOAC, 2016.

BASSAN, M.M.; MOURÃO FILHO, F.A.A.; ALVES, R.F.; BEZERRA, D.F.; COUTO, H.T.Z.; JACOMINO, A.P. Beneficiamento pós-colheita de lima ácida 'Tahiti' afeta sua qualidade e conservação. Ciência Rural, v.46, n.1, p.184-190, 2016. http://dx.doi.org/10.1590/0103-8478cr20141492

BENEVIDES, S.D.; RAMOS, A.M.; STRINGHETA, P.C.; CASTRO, V.C. Qualidade da manga e polpa da manga Uba. Ciência e Tecnologia de Alimentos, v.28, n.13, p.571-578, 2008. http://dx.doi.org/10.1590/S0101$\underline{20612008000300011}$

BORGES, V.; SOBRINHO, F.S.; LÉDO, F.J.S.; KOPP, M.M. Associação entre caracteres e análise de trilha na seleção de progênies de meios irmãos de Brachiaria ruziziensis. Revista Ceres, v.58, n.6, p.65-772,

2011. 
http://dx.doi.org/10.1590/S0034-

\section{X2011000600013}

BRASIL. Ministério da Saúde. Agência Nacional de Vigilância Sanitária. Métodos físico-químicos para análise de alimentos. Brasília: Ministério da Saúde, 2005.

BRASIL. Ministério da Agricultura, Pecuária e do Abastecimento. Instrução Normativa no 122, de 10 de setembro de 1999. Diário Oficial da República Federativa do Brasil, Brasília, 13 de setembro de 1999. Seção 1.

BRASIL. Normas Analíticas do Instituto Adolfo Lutz: métodos químicos e físicos para análise de alimentos. São Paulo: IAL, 2008.

BRITO, K.D.; SANTOS FILHO, J.I.; OLIVEIRA, H.B.L. ARAÚJO, B.G.; PAIXÃO NETO, E.; LIMA, F.C.S. Estudo experimental do limão 'Tahiti' (Citrus latifólia Tanaka): composição físico-química e de minerais da polpa in natura e do resíduo albedo. Revista Principia, n. 37, p. 64-70, 2017. http://dx.doi.org/10.18265/1517-

03062015v1n37p64-70.

CARVALHO, J.E.U.; NAZARÉ, R.F.R.; OLIVEIRA, W.M. Características físicas e físico-químicas de um tipo de bacuri (Platonia insignis Mart.) com rendimento industrial superior. Revista Brasileira de Fruticultura, v.25, n.2, p.326-328, $2003 . \quad$ http://dx.doi.org/10.1590/50100$\underline{29452003000200036}$

CHITARRA, M.I.F.; CHITARRA, A.B. Pós-colheita de frutas e hortaliças: fisiologia e manuseio. 2. ed. Lavras: UFLA, 2005.

COUTO, M.A.L.; CANNIATTI-BRAZACA, S.G. Quantificação de vitamina $C$ e capacidade antioxidante de variedades cítricas. Ciência e Tecnologia de Alimentos, v.30, Supl.1, p.15-19, $2010 . \quad$ http://dx.doi.org/10.1590/S0101$\underline{20612010000500003}$

DANTAS, A.L.; SILVA, S.M.; LIMA, M.A.C.; DANTAS, R.L.; MENDONÇA, R.M.N. Bioactive compounds and antioxidant activity during maturation of strawberry guava fruit. Revista Ciência Agronômica, Fortaleza, v.44, n.4, p.805814, 2013. http://dx.doi.org/10.1590/S1806$\underline{66902013000400018}$
FAGUNDES, G.R.; YAMANISHI, O.K. Características físicas e químicas de frutos de mamoeiro do grupo solo comercializado em 4 estabelecimentos de Brasília-DF. Revista Brasileira de Fruticultura, v.23, p.541-545, 2001. http://dx.doi.org/10.1590/S010029452001000300018

FERREIRA, D.F. Sisvar: A Guide for its Bootstrap procedures in multiple comparisons. Ciência \& Agrotecnologia, v.38, n.2, p.109-112, 2014. http://dx.doi.org/10.1590/S141370542014000200001

GOES, T.S.; CARMO, J.S.; BRAGA, T.R.; OLIVEIRA, M.M. T.; SILVA, L.R.; TORRES, L.B.V. Caracterização física e físico-química de frutos do limão "Tahiti" (Citrus latifolia T.) cultivados em Guaraciaba do Norte-CE. Cultivando o Saber, v.5, n.3, p.14-21, 2012.

GONDIM, P.J.S.; SILVA, S.M.; PEREIRA, W.E.; DANTAS, A.L.; CHAVES NETO, J.R.; SANTOS, L.F. Qualidade de frutos de acessos de umbucajazeira (Spondias sp.). Revista Brasileira de Engenharia Agrícola e Ambiental, v.17, n.11, p.1217-1221, 2013.

http://dx.doi.org/10.1590/S1415-

$\underline{43662013001100013}$

GUERRA, N.B.; LIVEIRA, A.V.S. Correlação entre o perfil sensorial e determinações físicas e químicas do abacaxi cv. Pérola. Revista Brasileira de Fruticultura, v.21, n.1, p.32-35, 1999.

INSTITUTO ADOLFO LUTZ. Normas analíticas, métodos químicos e físicos para análise de alimentos. 2. ed. São Paulo, 2005.

JAYAPRAKASHA, G.K.; PATIL, B.S. In vitro evaluation of the antioxidant activities in fruit extracts from citron and blood orange. Food Chemistry, v.101, n.1, p.410-418, 2007. http://dx.doi.org/10.1016/j.foodchem.2005.12.0 $\underline{38}$

KLUGE, R.A.; JOMORI, M.L.L.; EDAGI, F.K.; JACOMINO, A.P.; AGUILLAR, J.A.I. Danos de frio e qualidade de frutas cítricas tratadas termicamente e armazenadas sob refrigeração. Revista Brasileira de Fruticultura, v.29, n.2, p.233-238, 2007. 
MARTINS, K.S.; CARON, V.C.; BOFF, T.; CASTEJON, L.V.; BONNAS, D.S. Parâmetros físicos e químicos de limas ácidas 'Tahiti' e limões 'Galego' produzidos no cerrado brasileiro. Enciclopédia Biosfera, v.15 n.27; p. 194-199, 2018. http://dx.doi.org/10.18677/EnciBio 2018A64

MCATEE, P.; KARIM, S.; SCHAFFER, R.J.; DAVID, K. $A$ dynamic interplay between phytohormones is required for fruit development, maturation and ripening. Frontiers in Plant Science. v.4, n.1, p.17, 2013.

\section{http://dx.doi.org/10.3389/fpls.2013.00079}

MIRANDA, M.N.; JUNIOR, J.H.C. Desenvolvimento e qualidade da lima ácida Tahiti em Colorado do Oeste, RO. Revista Ceres, v.57, n.6, p.787-794, 2010.

NASCIMENTO, R.S.M.; CARDOSO, J.A.; COCOZZA, F.D.M. Caracterização física e físico-química de frutos de mangabeira (Hancornia speciosa Gomes) no oeste da Bahia. Revista Brasileira de Engenharia Agrícola e Ambiental, v.18, n.8, p.856-860, 2014.

http://dx.doi.org/10.1590/1807-

1929/agriambi.v18n08p856-860

PALIYATH, G.; MURR, D.P. Biochemistry of Fruits. In: PALIYATH, G.; MURR, D. P.; HANDA, A. K.; LURIE, S. Postharvest biology and technology of fruits, vegetables and flowers. Wiley-Blackwell Publishing, 2008. Cap. 3, p. 19-50.

PEREIRA, M.E.C.; CANTILLANO, F.F.; GUTIEREZ, A.S.D.; ALMEIDA, G.V.B. Procedimentos póscolheita na produção integrada de citros. Cruz das Almas: Embrapa Mandioca e Fruticultura Tropical, 2006.

PINHEIRO, A.M.; FERNANDES, A.G.; FAI, A.E.C.; PRADO, G.M.; SOUSA, P.H.M.; MAIA, G.A. Avaliação química, físico-química e microbiológica de sucos de frutas integrais: abacaxi, caju e maracujá. Revista Ciência e Tecnologia de Alimentos, v.26, n.1, p.98-103, $2006 . \quad$ http://dx.doi.org/10.1590/S0101$\underline{20612006000100017}$

RITZINGER, R.; SOARES FILHO, W.S.; CARVALHO, P.C.L. Evaluation of umbu-caja germplasm in the state of Bahia, Brazil. Crop Breeding and Applied Biotechnology, v.8, n.3, p.181-186, 2008. http://dx.doi.org/10.12702/1984-

7033.v08n03a01

SACRAMENTO, C.K.; MATOS, C.B.; SOUZA, C.N.; BARRETTO, W.S.; FARIA, J.C. Características físicas, físico-químicas e químicas de cajás oriundos de diversos municípios da região sul da Bahia. Magistra, v.19, p.283-289, 2007.

SANTOS, M.B.; CARDOSO, R.L.; FONSECA, A.A.O.; CONCEIÇÃO, M.N. Caracterização e qualidade de frutos de umbu-cajá (Spondias tuberosa $x \mathrm{~S}$. mombin) provenientes Do Recôncavo sul da Bahia. Revista Brasileira de Fruticultura, v.32, n.4, p.1089-1097, 2010. http://dx.doi.org/10.1590/S0100$\underline{29452011005000015}$

SILVA, D.F.P.; SALOMÃO, L.C.C.; SIQUEIRA, D.L.; BARBOSA, M.A.; VALLE, K.D.; OLIVEIRA, J.A.A. Correlação entre características físicas e químicas de frutos de manga 'Ubá'. Cultura Agronômica, v.27, n.2, p.356-362, 2018.

SILVA, D.F.P.; SILVA, J.O.C.; MATIAS, R.G.P.; RIBEIRO, M.R.; BRUCKNER, C.H. Correlação entre características quantitativas e qualitativas de frutos de pessegueiros na geração F2 cultivados em região subtropical. Revista Ceres, v. 60, n. 1, p.53-58, 2013. http://dx.doi.org/10.1590/S0034737X2013000100008

SILVA, D.F.P.; SIQUEIRA, D.L.; ROCHA, A.; SALOMÃO, L.C.C.; MATIAS, R.G.P.; STRUIVING, T.B. Diversidade genética entre cultivares de mangueiras, baseada em caracteres de qualidade dos frutos. Revista Ceres, v.59, n.2, p. 225-232, $2012 . \quad$ http://dx.doi.org/10.1590/S0034737X2012000200011

SOUZA, J.M.A.; ATAÍDE, E.M.; SILVA, M.S. Conservação pós-colheita de lima ácida 'tahiti' com uso de ácido giberélico, cera de carnaúba e filme plástico em condição refrigerada. Magistra, V.27, N.1, p. 122-129, 2015.

STROHECKER, R.; HENNING, H.M. Analisis de vitaminas: métodos comprobados. Madrid: $\mathrm{Paz}$ Montalvo, 1967.

TRUCOM, C. Doce Limão. São Paulo, 2005. Disponível em: www.docelimao.com.br/limaoorigemvariedades.htm. Acesso em: 13 maio 2018. 
VIANA, E.S.; REIS, R.C.; SENA, L.O.; SANTOS JÚNIOR, M.B.; SILVA, P.N.R. Produção de bananas-passa com frutos de variedades melhoradas e avaliação da qualidade físicoquímica e sensorial. Boletim Centro de Pesquisa de Processamento de Alimentos, v.35, n.1, p.110 , 2017.

http://dx.doi.org/10.5380/cep.v35i1.55944

Recebido para publicação em 27/07/2018

Revisado em 14/01/2019

Aceito em 31/01/2019 